\title{
Potential private sector involvement in supporting refugee livelihoods and self-reliance in Uganda: Annotated bibliography
}

Anna Louise Strachan

Consultant

31 March 2021

\section{Question}

What lessons have been learnt about the role the private sector can play in supporting refugee livelihoods and self-reliance in Uganda from 2016-2020?

\section{Contents}

1. Summary

2. Annotated Bibliography

5. References

The K4D helpdesk service provides brief summaries of current research, evidence, and lessons learned. Helpdesk reports are not rigorous or systematic reviews; they are intended to provide an introduction to the most important evidence related to a research question. They draw on a rapid desk-based review of published literature and consultation with subject specialists.

Helpdesk reports are commissioned by the UK Foreign, Commonwealth, and Development Office and other Government departments, but the views and opinions expressed do not necessarily reflect those of FCDO, the UK Government, K4D or any other contributing organisation. For further information, please contact helpdesk@k4d.info. 


\section{Summary}

There is some evidence of the private sector playing a role in supporting refugee livelihoods and self-reliance in Uganda during the period 2016-2020. However, a number of evaluations and research reports highlight the potential for greater private sector involvement, if existing constraints are addressed.

Key lessons identified in the literature include:

- Limited access to capital, as well as appropriate financing schemes, are key constraints to growth of the agribusiness sector (Mercy Corps, 2018).

- There is a need for more research, especially on market potential, to address the existing knowledge gaps on the role the private sector can play in supporting refugee livelihoods and self-reliance in Uganda (Mercy Corps, 2018).

- There is some wariness about implementing private sector-NGO partnerships, due to the different objectives of the private and NGO sectors (Fleming, 2020).

- Longer term projects are more likely to have an impact than short term projects, as it takes time for private sector-NGO partnerships to start operating efficiently (Fleming, 2020)

- Access to natural resources required for agri-business, such as land and water need to receive more attention from NGOs and donors (Mercy Corps, 2019).

- There is a need for guidelines on the monitoring and evaluation of humanitarian adaptations of market systems development programming (Levine \& Bectone, 2019).

- Local actors should be involved in the design, and assessment of investment opportunities and risk of interventions to increase project impact (Mercy Corps, 2021).

The literature reviewed consists largely of rigorous evaluations or of summaries of evaluations, primarily of pilot projects. However, the studies identified are largely gender and disability blind.

\section{Annotated bibliography}

Socioeconomic status and livelihoods of refugees in a self-reliance situation in Kyangwali refugee settlement

Ayine, R; Tumwine, FR; Kabumbuli, R (2017). Makerere University,Kampala, Uganda

This is a case study, using a cross-sectional survey utilising pretested questionnaires and interview schedules, which examines the socioeconomic status and livelihoods of refugees in a self-reliance situation in the Kyangwali refugee settlement in Kikuube District (formerly Hoima District) in western Uganda. The settlement was selected due to its being one of the oldest locations where the self-reliance strategy had been implemented and many of its refugees being long-time residents. The main organisation involved was Makerere University, Kampala. There was no private sector involvement. 


\section{Key findings}

Analysis of responses revealed that 80.5 per cent of those surveyed were involved solely in the cultivation of subsistence crops, with the remaining 19.5 per cent pursuing other activities such as boda-boda riding, small scale trade, tailoring or brewing local gin. The study further established that 76.7 per cent of respondents were merely surviving and that 83.1 per cent of those refugees in the surviving category were involved in subsistence crop cultivation as their main livelihood activity. The main reasons given by informants for this situation was a lack of education and skills among the majority of refugees.

\section{Conclusion and recommendations}

The study concluded:

- Efforts to promote refugee livelihoods will fail if refugees are not empowered to construct gainful livelihoods.

- There is a need to create an enabling environment that will promote individual and collective innovation and opportunities. This can be done through diversifying livelihood activities and encouraging the involvement of refugees in multiple sources of income.

- There is the need to revamp and remodel the subsistence crop-cultivation in the settlement into a market driven production that can guarantee high production levels, quality and subsequently more income.

- Actors on refugee issues need to abandon the notion that refugee self-reliance is contingent upon sufficient food production alone.

\section{'Refugees asked to fish for themselves': The Role of Livelihoods Trainings for Kampala's Urban Refugees}

Easton-Calabria, E (2016). University of Oxford

This is a study on livelihood training being carried out in accordance with the 2016-2020 Refugee and Host Population Empowerment (ReHoPE) Strategic Framework that was formulated by UNHCR on behalf of the United Nations Country Team and World Bank. It employs a mixedmethods approach consisting of semi-structured in-depth interviews, focus group discussions (FGDs), basic demographics interviews, and participant observation. Livelihoods training at four organisations was observed, and individual refugees were also 'followed' in the process, from participating in training to opening their own businesses. The fieldwork was carried out in Kampala over a period of three months. The main organisation involved was UNHCR and there was no private sector involvement.

\section{Key findings}

The main points highlighted by the study were that while the training provided was apposite and embraced by refugees, being seen as a positive experience even when it did not result in employment, the main obstacles to using the new skills obtained were a lack of access to capital and lack of access to markets. These challenges were noted by 90 per cent of refugee participants and 100 per cent of organisations. All organisations cited hairdressing and tailoring as having a high employment success rate, as did mushroom-growing, where offered. This was 
due to there being no capital requirement. Notwithstanding these cases, it is apparent that completing skills training does not directly lead refugees into employment.

\section{Conclusion and recommendations}

Once skilled, refugees are faced with an inability to accrue capital to start or expand small businesses, which impedes their livelihoods' creation. Those who pursue economic activities they are trained in often face challenges in finding markets for their goods or services within Kampala. Addressing these barriers in addition to adapting livelihood training based on the results of a comprehensive market survey of Kampala is vital for achieving successful refugee livelihoods in the city.

\section{Recommendations - Access to Capital:}

- Presenting options for Ugandan financial institutions to incorporate refugees into their clientele is an important way to increase refugees' access to microfinance.

- As an intermediary step for including refugees as a banked population, organisations serving refugees could act as financial guarantors for refugee entrepreneurs.

- Partnerships with Ugandan banks or MFIs could be formed and money pools that currently exist in organisations such as JRS and InterAid for loans used instead as a guarantee for loan repayment.

- Partnerships between organisations serving refugees and non-profit MFls that traditionally serve nationals could also help refugees access loans by including refugees in an existing national client base.

- More research on micro-finance and savings programme led by refugees themselves is needed.

\section{Recommendations - Access to Markets:}

- Uganda should undertake a comprehensive market assessment in order to develop targeted livelihoods interventions, including appropriate livelihoods skills training.

- Steps to build the resilience of refugees engaged in small businesses should continue to feature in livelihood training, and particular skills training should be strategically located in order to avoid the risk of market saturation.

- International markets targeting fair-trade goods produced by refugees should be explored.

- Domestic markets should be as fully exploited as possible before export markets are tapped.

\section{Determinants of refugee livelihood strategies in Rwamwanja refugee settlement, Kamwenge District \\ Nakachwa, C. (2016). International Health Sciences University, Kampala, Uganda}

This dissertation's objectives were to determine the different social factors affecting livelihoods pursued by the refugees in the settlement, to assess the economic factors that influence their choice of livelihood strategies, and to establish the institutional factors that determine their choice of livelihood strategies. The study was cross-sectional in nature. Both qualitative and quantitative data was collected for analysis of the refugee livelihood context. Qualitative data was used to collect information on the knowledge, attitude and practices of refugees on the issues affecting their livelihoods. Quantitative data was used to analyse to what extent different factors determine refugee livelihood options. The study was restricted to Rwamwanja refugee settlement in south 
west Uganda and covered 40 villages. The main organisation involved was IHSU, endorsed by the Prime Minister's office. There was no private sector involvement.

\section{Key findings:}

- Farming (52.6 per cent) is the most valued source of livelihoods, followed by assistance from NGOs (35.6 per cent) and wages/salaries (17.8 per cent). Farming's prominence is due to the availability of free land, and the fertile soil and favourable weather conditions of the settlement.

- A significant number of respondents also derive their livelihoods from animal husbandry activities, petty trade, remittances from relatives, woodwork and wood products.

- There was no association between gender, age and the livelihood activity the refugees considered important or not important, though there was an association between the marital status of refugees and their choice of livelihoods.

- There is a significant association between refugees that moved from one place to another within the settlement and their choice of livelihoods. Respondents emphasised that membership in social groups such as mother to mother support, savings, ethnic and religious groups improved their chances of getting different forms of support that contributed towards their livelihoods.

- The research found that number of household members, state of literacy and level of education are not associated with the livelihoods of refugees in any way.

- The research shows that a majority of the respondents, 91.6 per cent, owned land legally in the settlement. (NB - this is contradicted by other studies reviewed in this annotated bibliography which state that refugees only have user rights to land - they cannot sell it or use it as collateral for credit).

- The most popular income generating activity was crop production and animal husbandry at 25.7 per cent and 12.6 per cent respectively. These were followed by retail shops, craft/art and hairdressing at 11.5 per cent, 9.4 per cent and 3.4 per cent respectively. Tailoring, other forms of IGAs and mechanics/locomotion were 8.9 per cent, 8.9 per cent and 3.7 per cent respectively.

\section{Conclusion and recommendations}

- A sustainable livelihoods approach provides a more practical way to address protracted refugee situations, as opposed to unsustainable physical support.

- Development agencies need to run a thorough analysis of the target population in context, so as to enable equitable and efficient use of resources and prioritise needs.

- Social groups provide safety social nets for refugees especially in hard times. The support from social groups ranges from social, financial, material and religious to emotional/psychosocial support.

- Accessibility to both internal and external markets, communication and transport greatly affects and influences livelihoods of refugees.

- Structures and processes in place will always determine what, how, why and when several livelihoods are or would be available and derived. Laws and policies affect how we behave socially, physically and economically. 


\section{Social recommendations:}

- Social associations and groups should be supported through either physical or financial support as they play a key role in refugee livelihoods.

\section{Economic recommendations:}

- Development and humanitarian agencies venturing into livelihoods programming should aim at improving the already existing systems and markets, so as to easily transition the refugees into self-reliance. In addition, improving the road network within the settlement can boost economic lives of refugees.

\section{Institutional recommendations:}

- Since agriculture is the most popular livelihood engaged in by the refugees, development and humanitarian agencies should channel substantial amounts of funding to empower refugees to get greater value for their agricultural investments.

\section{Sustainable livelihoods in Ugandan refugee settings}

Rohwerder, B (2016). GSDRC

The report is a desk-based literature review, largely based on grey literature, which set out to show the factors that help or inhibit sustainable livelihoods in refugee settings with a focus on Uganda. The report finds that refugee livelihood programming should have localised contextual awareness; refugee and local input; partnerships with host institutions; and long term and predictable funding.

In terms of partnerships with the private sector it finds that partnerships between governments, development actors and the private sector are important for developing sustainable refugee livelihoods. The report provides two examples of how the private sector in Uganda has provided livelihood opportunities for refugees. One is as mobile money unit agents for Orange Uganda Limited and the other is through the Koboko Partnership, a public-private partnership targeting 7,500 refugee and host community households in modern, commercial-scale agriculture.

\section{Key findings:}

Factors supporting sustainable livelihoods in refugee settings:

- A favourable policy environment

- Social capital and networks

- Collective efforts

- Training and skills development

- Access to credit

- Diverse livelihood strategies

- Partnerships with the private sector

- Refugee profiles

Factors inhibiting sustainable livelihoods in refugee settings:

- Unfavourable political and policy context 
- Lack of access to capital and markets

- Capacity and willingness of refugees

- Poverty of host areas

- Negative gender stereotypes and discriminatory attitudes

\section{A step towards resilience: pioneering market systems development in humanitarian response Mercy Corps (2019).}

This report is an evaluation of a 12-month pilot project implemented by Mercy Corps, Palladium Group and Danish Church Aid. The evaluation finds that the pilot saw considerable success within the 12-month period, demonstrating early market systems change in the form of behavioural shifts among actors at all stages of the agricultural value chain. It also demonstrated potential to increasing farmers' agricultural incomes in the sub-region in the long term. However, the pilot had a limited scope and timeframe, and there are many remaining market challenges and information gaps.

\section{Key findings:}

- Behaviour changes were observed among all market actors, and the evaluation considers these to be positive indications of early market systems change.

- Social capital and relationships are key in terms of accessing goods and information. The pilot incentivised host community farmers to provide access to land to refugee farmers by offering free tillage services on one acre of their land for every five acres provided to refugee farmers. This and other targeted activities on building and strengthening market linkages between key actors were linked to farmers' increased access to resources, improved efficiencies in the supply chain, increased knowledge of farming practices and ultimately improved social capital as a contributor to household resilience.

- Improving market opportunities requires a multi-year approach. Within 12 months, the pilot achieved significant results, especially relating increased use of improved inputs and market engagement. However, there were unexplored sales channels that offer greater market opportunities, and greater profitability to farmers than those targeted under the pilot. Though further analysis is required, filling these market information gaps, as well as collecting data on yields, losses, and prices over time could help support the business case for farming as a livelihood strategy.

\section{Recommendations:}

- Financing models such as trade finance, agriculture sector loans, and village savings and loans groups should be prioritised for future research and programming.

- The issue of unfavourable market prices requires further learning by market actors. Many of the pilot's interventions were designed under the assumption that supporting farmer linkages with larger city-based markets would offer the greatest opportunity to farmers. However, the results from the pilot suggested local sales channels may be more profitable for farmers. An in-depth assessment of potential sales channels, market dynamics, pricing structures, and transaction costs would help to foster a more 
comprehensive understanding of the most profitable and sustainable market avenues for farmers.

- Future programming needs to address cross-cutting constraints such as access to finance, climate change and poor infrastructure. In particular, supporting access to finance interventions, and identifying and encouraging market-driven solutions to challenges around infrastructure, natural resources and transportation (including distribution and aggregation).

- Greater consideration needs to be given to the availability of natural resources. Sufficient water for production, land quality and size, and environmental protection techniques, such as agroforestry and the use of organic principles, are all vital for achieving successful yields, particularly with regard to climate change. Further targeted longer-term interventions and greater budget allocation is required to address these challenges.

\section{ReHope: End of pilot phase evaluation report Mercy Corps Uganda (2018).}

This is a mixed methods endline evaluation of the ReHope pilot project 'Demonstrating a Market System Approach in Bidibidi and Palorinya Settlements (ReHope),' in the West Nile region of Uganda, and the efficacy of using a market systems inspired approach as part of humanitarian response. The pilot project's goal was contributing to increasing refugee and host community farmers' incomes (economic welfare) in the region, through growth of the agribusiness sector. The pilot targeted 3,500 host community and 1,500 refugee farmers within Yumbe and Moyo districts. For the quantitative component of the evaluation, 490 individual farmers were interviewed from host (216 farmers) and refugee (274 farmers) communities in Moyo and Yumbe districts. In total, 47 qualitative interviews and/or focus groups were conducted at endline, which included host and community farmers, private sector companies (both partners and non-partners), innovation centre partners, refugee welfare committees, OPM, UNHCR, donors and NGOs.

\section{Key findings/lessons learned:}

- Targeted activities under ReHope that focused on building and strengthening relationships between key actors throughout the value chain (e.g. facilitating refugee land access on host community land) were clearly linked to farmers' increased access to resources, improved efficiency within the supply chain and increased knowledge and understanding of farming practices.

- Greater consideration needs to be given to the availability of resources. Sufficient water for production, land quality and size, and environmental protection techniques, such as agroforestry and the use of organic principles, are all essential components for achieving successful yields, particularly with regard to climate change. While consideration for these natural resource factors can be embedded in programme design via climate smart approaches, further targeted interventions and greater budget allocation is required to tackle these challenges.

- Price remained a key barrier for farmer uptake of improved inputs and tillage services. Limited access to capital, as well as appropriate financing schemes, were seen as key constraints to growth of the agribusiness sector by all market actors. The evaluation finds that further research and investment is required in this area. 
- Gaps in understanding, related to market potential, as well as the most viable and profitable sales channels for West Nile farmers, remain. Moreover, more time is required to gather evidence on the true cost benefit to farmers in using improved inputs and services. Capturing this information over multiple years to build the business case for farming could be a powerful tool to engage farmers and leverage buying from agrodealers, seed companies and offtakers, as well as external actors, such as government and donors.

\section{The power of markets to support refugee economic opportunities in West Nile, Uganda} Mercy Corps. (2017). Mercy Corps: Portland, Oregon

This is a briefing paper, summarising project findings for a Mercy Corps project (ReHope) in West Nile, Uganda. The project focused on the provision of subsidies to local agro-dealers, promoting land-sharing between refugees and host communities, and working with produce trading companies to attract them to the project area.

There are two ways that private sector partnerships were a feature of the ReHope Project:

- Working with local agro-dealers to enable them to afford agro-products and to sell them at a lower price to farmers

- Working with produce trading companies to attract them to the project area

The briefing paper emphasises how the project leveraged the power of markets to foster durable income opportunities in refugee areas in the West Nile region.

\section{Key findings:}

- There was an increase in market activities resulting in an increase in the spending power of refugees

- Some refugees are starting to make business investments in the settlements

- The growth in refugees' spending and investments is likely to continue growing and to provide opportunities for surrounding host communities

\section{Conclusion and recommendations:}

- Markets can work for refugees given they have support.

- Transitioning away from in-kind aid for basic needs and livelihoods and embracing a reduction in subsidies to encourage long-term market investments

- Reducing funding siloes and increasing project timeframes so that aid actors can address market constraints and protracted needs

- Seeking opportunities to employ market systems development approaches, leveraging the expertise of actors working in both development and humanitarian spaces

- Capturing market systems learning for current and future refugee responses in West Nile 


\section{Partnership Potentials: Investigating Ugandan private sector attitudes to partnerships with INGOs to co-create community-based innovations}

Fleming, J.A (2020). University of Copenhagen, Copenhagen, Denmark

This is a thesis for a Master's in Disaster Management, using ten semi-structured interviews administered to Ugandan business leaders, exploring their attitudes and experiences in partnering with INGOs. The study also made use of existing literature to complement its findings. Uganda was chosen as the country of focus due to its long history of INGO activity.

From the findings of the study, private sector-INGO partnerships are still approached cautiously due to the view that the private sector is out to make profit, in contrast to NGOs, which are 'notfor-profit.' The findings also indicate an ever-blurring line between the private sector and INGOs, with increased INGO market competition and a push for sustainability. Additionally, the study highlights the benefits of partnerships, approaches to partnerships, and the preferences for partnerships based on duration.

\section{Core findings:}

- All those interviewed believed it was essential for businesses to engage in humanitarian action or community-based assistance

- All interviewees found it important to have collaborative partnerships between the private sector and those working for not-for-profits

- There is a preference for longer-term partnerships, in part due to the length of time it takes to get a partnership up and running

- There is a need to maintain good communication with partners, regardless of the length of the partnership

- A bottom-up approach was found to be the best approach when designing programmes, with the end users expressing their needs, and programmes being developed based on these needs

- Longer-term partnerships between the private sector and INGOs allow a more strategic and deeper relationship with the INGO

- Respondents found partnerships with INGOs more complex than working with other private sector actors

\section{Conclusion and recommendations}

- Benefits of private sector-NGO partnerships include capacity building, access to funding, access to new markets, and an increase in business exposure.

- The study recommends undertaking another research study to focus on the different types of private sector models and how partnerships with INGOs would look given the strengths and challenges of each of these models.

\section{Facing up to the Challenges: Blending Market and Humanitarian Support for Refugees in Uganda \\ Levine, S; Bectone, G. (2019). Mercy Corps. Portland, Oregon}

This is a thought piece focusing on Mercy Corps learning from one of its projects in Uganda. The project was on the long-term impacts of local businesses and market institutions on their communities. The article analyses the use of market systems development (MSD), which 
addresses constraints in the market in order to create widespread positive impact. MSD is analysed in Uganda in a context where refugee populations, mainly from South Sudan, interact with host communities.

\section{Key findings:}

- The use of MSDs in crises is still new and there is limited existing research on the topic

- The MSD approach used had some positive impacts:

- National seed companies began working with local agro-dealers

- Agro-dealers made a wide range of products available and expanded their businesses

- Designing MSD programmes is complex

- There is a lack of guidance notes/ tools on the development of MSD programmes

\section{Conclusion and Recommendations:}

- Adaptations of MSD for crises and refugee situations offer enough promise to warrant their wider use

- If humanitarian and development agencies take their commitments to the nexus seriously, then they need to find ways to move beyond rhetoric and collaborate on markets in crises

- With the increased need for humanitarian and development interventions set to continue, sector wide collaboration is needed to meet the diverse needs in mutually compatible ways

- There is an urgent need to develop guidance on monitoring and evaluation for humanitarian adaptations of MSD programming

One year on: Paying for Darkness. Strengthening Solar Markets for Refugees in Uganda Mercy Corps. (2021). Mercy Corps: Portland, Oregon

This is a summary of a project evaluation for a project that aimed to sell refugees in Uganda offgrid solar units at subsidised prices. The evaluation is based on key informant interviews with programme field teams, sales agents, community leaders and community members.

There was no mention of private partnerships, but the programme implementers partnered with two suppliers of off-grid solar units.

\section{Key findings:}

- Sales outperformed initial targets

- The high sales rate indicated the success and potential of a market systems approach for the solar energy units, even in remote and underserved refugee market

- Mercy Corps met their intended outcomes and was on track to outperform their targets

- The two suppliers of solar units intended to remain in the market, to continue working with the refugees and host communities as suppliers 


\section{Conclusion:}

- Local actors should be involved in the design and assessment of investment opportunities and in risk assessments, as this increases project impact.

\section{A Strategy for Engaging the Private Sector in Uganda's Refugee Response. Validation Meeting}

Palladium. (2020).

This is a validation meeting presentation for a study to develop a private sector engagement srategy for CRRF (Comprehensive Refugee Response Framework) and make recommendations related to private sector development in Refugee Hosting Districts. The study used a mixed methods approach, combining a desk review, field trips, a company survey and a round table participation and prioritisation exercise.

\section{Key findings:}

- A policy review indicates supportive integration policies, and a conducive legal environment for financial service providers in Refugee Hosting Districts (RHDS), and regional trade agreements have the potential to boost economic opportunities in RHDs

- Most companies in the target area are focused on agriculture, trade and processing with 82 per cent of the surveyed companies already working in RHDs. Most companies were also selling to/ sourcing from RHDs

- 83 per cent of respondents indicated growing their business as the main reason for operating in RHDs, 4 per cent were involved in RHDs due to grants, and only 11 per cent due to CSR

- External companies could be incentivised to move into RHDs if constraints were addressed

- Findings from the field indicate low levels of investment, poor access to finance for market actors, agriculture not being commercialised in RHDs, low purchasing power of consumers, and an undeveloped labour market

Current challenges in RHDs highlighted in the presentation are:

- Poor quality and volumes of agriculture coupled with limited engagement of the private sector lead to low demand for products produced in these areas

- Undeveloped labour markets with a small and informal local private sector lead to poor purchasing power of consumers

\section{Conclusion and recommendations:}

- There is a need to develop a policy environment that is supportive of refugee selfreliance and focused on the private sector with funding and enforcement

- The aim should be to increase private sector presence in RHDs and develop incentives for engagement by larger companies

- There is a need to work to reduce corruption, fraud, a lack of social trust, and to address issues such as dispersed farmers, distances to market, and the cost of doing business 
- There is a need to ensure development partners are using a private sector lens to reduce market distortion and prioritise RHDs

- There is a need to increase coordination between local and national government, the private sector, and development actors

Uganda refugee hosting districts - Investment profiles (Yumbe, Kyegegwa, Kiryandongo, Kamwenge, Hoima, Arua, Adjumani)

UNDP. (2017).

This is a series of investment profiles for RHDs in Uganda, produced by UNDP in collaboration with the Uganda Investment Authority, in preparation for the 2017 Uganda Solidarity Summit. Their purpose was to 'mobilise additional investments and commitments to support the country's efforts towards a more diversified and resilient economy that integrates refugees.' All the districts for which investment profiles were produced have a significant refugee population, with the highest number of refugees in Adjumani at 94 per cent of the population, and the lowest number in Hoima, standing at 7.2 per cent.

The main economic activity of residents in all the areas for which there is an investment profile is agriculture, with most planting the same types of tradeable crops. Other livelihood activities include fishing and trading, with both men and women involved in activities such as dressmaking, fishing, and trading fish and other commodities. In most of the districts, the majority of refugees are involved in some form of economic activity. Some refugees have been allocated plots of land to farm.

In terms of potential for investment, abundant natural resources and an enabling environment are cited as the main opportunities for investment in all the districts. Availability of minerals, water resources, arable land and wetlands with tropical climates are listed as indicators of the potential of the districts. Government support in terms of incentives for large-scale investments in sectors like agriculture is also emphasised. However, the level of support offered by the local government varies from district to district. The availability of land, nature of available resources, and the demography of each district is a determinant of the nature of investment opportunities in each district. The main investment opportunities in the districts are:

- Tourism

- Youth technical skills and capability enhancement

- Commercial agriculture

- Tree planting and tree nurseries

- Agribusiness

At the end of most of the district profiles, a list of existing investors is provided. 


\section{References}

Ayine, R., Tumwine, F.R., \& Kabumbuli, R. (2017). Socioeconomic status and livelihoods of refugees in a self-reliance situation in Kyangwali refugee settlement. Kampala: Makerere University. https://www.ajol.info/index.php/gjg/article/view/162539

Easton-Calabria, E (2016). 'Refugees asked to fish for themselves': The Role of Livelihoods Trainings for Kampala's Urban Refugees. Oxford: University of Oxford.

https://www.unhcr.org/research/working/56bd9ed89/refugees-asked-fish-themselves-rolelivelihoods-trainings-kampalas-urban.html

Fleming, J.A. (2020). Partnership Potentials: Investigating Ugandan private sector attitudes to partnerships with INGOs to co-create community-based innovations. Copenhagen: University of Copenhagen.

https://static1.squarespace.com/static/5d7fba1a7dc0f278f09832df/t/5fa904834e5ce030c7c7eed5 /1604912263535/Fleming_2020_RIL+Report_Uganda+Private+Sector+INGO+Partnerships.pdf

Levine, S \& Bectone, G. (2019). Facing up to the Challenges: Blending Market and Humanitarian Support for Refugees in Uganda. Portland, Oregon: Mercy Corps.

https://www.mercycorps.org/sites/default/files/2020-01/Facing_Up_to_the_Challenges_final.pdf

Mercy Corps. (2021). One year on: Paying for Darkness. Strengthening Solar Markets for Refugees in Uganda. Portland, Oregon: Mercy Corps.

https://www.mercycorps.org/sites/default/files/2020-01/Paying_for_Darkness_Uganda_FINAL.pdf

Mercy Corps (2019). A step towards resilience: pioneering market systems development in humanitarian response. Kampala: Uganda. https://www.mercycorps.org/researchresources/step-towards-resilience

Mercy Corps. (2018). ReHope: End of pilot phase evaluation report. Kampala: Uganda.

Mercy Corps. (2017). The power of markets to support refugee economic opportunities in West Nile, Uganda. Portland, Oregon: Mercy Corps.

https://www.mercycorps.org/sites/default/files/2020-

05/West_Nile_Refugee_Markets_Brief_Feb2018.pdf

Nakachwa, C. (2016). Determinants of refugee livelihood strategies in Rwamwanja refugee settlement, Kamwenge District. Kampala: International Health Sciences University. http://dspace.ciu.ac.ug/handle/123456789/1157

Palladium. (2020). A Strategy for Engaging the Private Sector in Uganda's Refugee Response. Validation Meeting. Palladium.

Rohwerder, B. (2016). Sustainable livelihoods in Ugandan refugee settings (GSDRC Helpdesk Report). Birmingham, UK, University of Birmingham. http://www.gsdrc.org/wpcontent/uploads/2016/10/HDQ1401.pdf

UNDP. (2017). Uganda refugee hosting districts - Investment profiles. Kampala: UNDP. https://www.ug.undp.org/content/uganda/en/home/library/SustainablelnclusiveEconomicDevelop mentProgramme/RefugeehostingdistrictsInvestmentProfiles.html 


\section{Suggested citation}

Strachan, A.L. (2021). Potential private sector involvement in supporting refugee livelihoods and self-reliance in Uganda: Annotated bibliography. K4D Helpdesk Report. Brighton, UK: Institute of Development Studies. DOI: 10.19088/K4D.2021.072

\section{About this report}

This report is based on six days of desk-based research. The K4D research helpdesk provides rapid syntheses of a selection of recent relevant literature and international expert thinking in response to specific questions relating to international development. For any enquiries, contact helpdesk@k4d.info.

K4D services are provided by a consortium of leading organisations working in international development, led by the Institute of Development Studies (IDS), with Education Development Trust, Itad, University of Leeds Nuffield Centre for International Health and Development, Liverpool School of Tropical Medicine (LSTM), University of Birmingham International Development Department (IDD) and the University of Manchester Humanitarian and Conflict Response Institute (HCRI).

This report was prepared for the UK Government's Foreign, Commonwealth and Development Office (FCDO) and its partners in support of pro-poor programmes. Except where otherwise stated, it is licensed for non-commercial purposes under the terms of the Open Government Licence v3.0. K4D cannot be held responsible for errors, omissions or any consequences arising from the use of information contained in this report. Any views and opinions expressed do not necessarily reflect those of FCDO, K4D or any other contributing organisation.

(C) Crown copyright 2021.

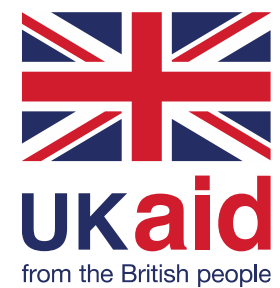

